\title{
Influence of Shear on Rotation Capacity of Reinforced Concrete Members Without Shear Reinforcement
}

\author{
by Rui Vaz Rodrigues, Aurelio Muttoni, and Miguel Fernández Ruiz
}

The influence of shear on the rotation capacity of one-way slabs without shear reinforcement is investigated in this paper by means of an experimental study. The experimental program consisted of 11 slab strips $8400 \mathrm{~mm}$ (331 in.) long and $450 \mathrm{~mm}$ (17.7 in.) thick with a flexural reinforcement ratio of $0.79 \%$. The rotation capacity was investigated for various values of the shear span and for two types of flexural reinforcement (hot-rolled and cold-worked bars). The specimens developed shear failures with and without yielding of the flexural reinforcement and one specimen failed in flexure with rupture of the tensile reinforcement. The results clearly show that the rotation capacity at failure is governed by shear. Based on the test results, and considering the principles of the critical shear-crack theory (CSCT), an analytical expression is proposed to estimate the rotation capacity of one-way members without transverse reinforcement accounting for shear.

Keywords: critical shear-crack theory; ductility; plastic hinges; shear strength; tests.

\section{INTRODUCTION}

Traditionally, the rotation capacity of one-way slabs without shear reinforcement is expressed as a function of the depth of the compression zone and the ductility of the flexural reinforcing steel for most theoretical models ${ }^{1-3}$ and codes of practice. $^{4,5}$ This is justified because failure develops in flexure by crushing of the concrete in compression or by rupture of the tensile reinforcement. ${ }^{1}$ Failures in flexure typically lead (provided that the minimum and maximum amounts of flexural reinforcement are respected) to a very ductile behavior, with a large capacity to redistribute inner forces within a structural system. A similar behavior is also observed for members with sufficient transverse reinforcement. ${ }^{6}$

On the contrary, a shear failure in a member without transverse reinforcement typically leads to a small rotation capacity, thus limiting the possibility to redistribute inner forces within a structural system. Shear failures not only develop for members whose flexural reinforcement remains elastic, but also can develop once the flexural strength is reached and the reinforcement yields. Such cases are shown in Fig. 1 (shaded area) with the help of Kani's valley. ${ }^{7}$

Due to the limited rotation capacity at ultimate, shear failures in members without transverse reinforcement are significant with respect to the strength of statically redundant structures (as some level of ductility is needed to develop the full structural strength). This fact is illustrated in Fig. 2(a), where the influence of shear is shown for three different cases. Cases A and B correspond to statically determinate structures where failure develops before (Case A) and after (Case B) yielding of the flexural reinforcement. In the first case, shear governs the strength (and thus the deformation capacity) of the member, whereas in the second case, shear governs the ductility. In Case $\mathrm{C}$ (statically redundant structure), shear governs both the strength and the ductility because the (a)

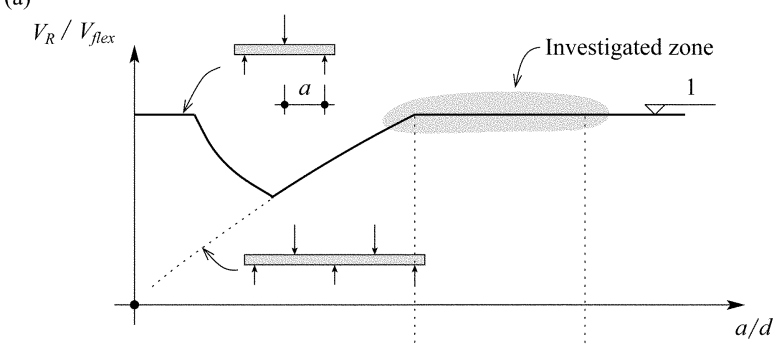

(b)

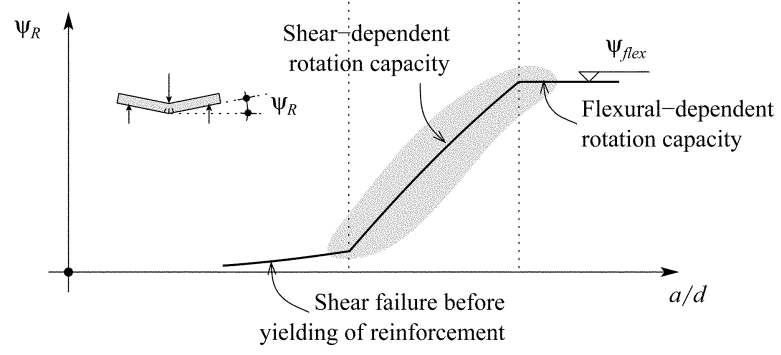

Fig. 1-Rotation capacity of one-way slabs: (a) Kani's valley ${ }^{7}$ and region of study; and (b) rotation capacity of plastic hinges governed by shear or flexure.

member does not have sufficient rotation capacity to develop its full structural strength. Cases where the rotation capacity of plastic hinges may limit the strength of statically redundant structures are, for instance, deck slab of bridges, top slabs of cut-and-cover tunnels, or braced walls (refer to Fig. 2(b)).

The influence of shear on the deformation capacity (or, conversely, of the deformation of a member on its shear strength) for reinforced concrete (RC) members without transverse reinforcement has previously been demonstrated by the critical shear-crack theory (CSCT) ${ }^{8,9}$ This behavior has been verified experimentally for members failing in shear before yielding of the flexural reinforcement. ${ }^{9}$ According to the CSCT, a shear failure is also possible after yielding of the flexural reinforcement because the increase in the width of the cracks (due to increasing rotations at the plastic plateau) limits the strength of the various shearcarrying mechanisms. ${ }^{9}$ An experimental verification of this has not been previously possible, however, because scanty experimental data is available on this topic. This paper is addressed to this issue, presenting the results of 11 slab strips without stirrups failing in shear before and after yielding of

ACI Structural Journal, V. 107, No. 5, September-October 2010.

MS No. S-2007-264.R3 received September 13, 2009, and reviewed under Institute publication policies. Copyright (C) 2010, American Concrete Institute. All rights reserved, including the making of copies unless permission is obtained from the copyright proprietors. Pertinent discussion including author's closure, if any, will be published in the JulyAugust 2011 ACI Structural Journal if the discussion is received by March 1, 2011. 
$\overline{\text { Rui Vaz Rodrigues is a Lecturer and Research Scientist at the Instituto Superior }}$ Técnico (IST), Technical University of Lisbon, Lisbon, Portugal. He received his diploma in civil engineering from IST in 2002 and his PhD from the École Polytechnique Fédérale de Lausanne (EPFL), Lausanne, Switzerland, in 2007. His research interests include shear, punching shear, and the structural assessment of reinforced concrete bridge deck slabs.

ACI member Aurelio Muttoni is Professor and Head of the Structural Concrete Laboratory, École Polytechnique Fédérale de Lausanne. He received his diploma and $P h D$ in civil engineering from the Swiss Federal Institute of Technology, Zurich, Switzerland, in 1982 and 1989, respectively. His research interests include the theoretical bases of the design of reinforced concrete structures, shear and punching shear, fiber-reinforced high-strength concrete, soil-structure interaction, and the conceptual design of bridges.

Miguel Fernández Ruiz is Lecturer and Research Scientist at the École Polytechnique Fédérale de Lausanne. He received his diploma in civil engineering from the Polytechnic University of Madrid, Madrid, Spain, in 2001 and his PhD from the same university in 2004. His research interests include the serviceability behavior of structures, bond, shear and punching shear, and the modeling of structural concrete using stress fields.

the flexural reinforcement. Based on these results, and using the CSCT principles, an analytical expression to estimate the rotation capacity of one-way members accounting for shear is proposed.

\section{RESEARCH SIGNIFICANCE}

Currently, the design of one-way slabs without transverse reinforcement does not consider the influence of shear on the ductility of the member. As a consequence, unsafe estimates of the strength for statically redundant structures may result. This paper introduces the results of an experimental study investigating the influence of shear on the rotation capacity of plastic hinges. Based on these results, and according to the principles of the CSCT, a rational approach for estimating the rotation capacity of such members is proposed.

\section{Specimens}

\section{EXPERIMENTAL PROGRAM}

The tested specimens were slab strips (beams) with a constant rectangular section $450 \times 250 \mathrm{~mm}$ (17.7 x 9.84 in.) and a total length of $8400 \mathrm{~mm}$ (331 in.), as shown in Fig. 3. The top and bottom longitudinal reinforcement for all specimens consisted of four bars $16 \mathrm{~mm}$ (5/8 in.) in diameter, which were placed in a single layer to reproduce the usual reinforcement layout of one-way slabs. The flexural reinforcement ratio of the specimens was thus $\rho=0.79 \%$. The effective depth (distance from the extreme compression fiber to the centroid of the longitudinal tensile reinforcement) was $409 \mathrm{~mm}$ (16.1 in.) for all of the specimens. The beams were simply supported, with a main span of $6000 \mathrm{~mm}$ (236 in.) and a cantilever length of $2000 \mathrm{~mm}$ (78.7 in.).

Two loads were applied by means of two independent hydraulic jacks: $P_{1}$ at midspan, and $P_{2}$ at the tip of the cantilever (Fig. 3). The load was introduced at midspan through a steel plate $100 \times 250 \times 30 \mathrm{~mm}$ (3.94 x 9.84 × 1.18 in.). At the tip of the cantilever, the load was introduced using a system composed of two steel plates of $300 \times 450 \times 50 \mathrm{~mm}(11.8 \times$ $17.7 \times 1.97$ in.), allowing both to push and pull at that point. The bearings of the specimens were composed of two rollers allowing horizontal displacements. The beams were horizontally restrained at the tip of the cantilever. They were thus statically determinate (Fig. 3), but the static system allowed for introducing a hogging or sagging moment at the intermediate support.

No shear reinforcement was placed between the applied load $P_{1}$ and the intermediate support; but outside this region, stirrups were provided to prevent shear failure (Fig. 3). The (a)

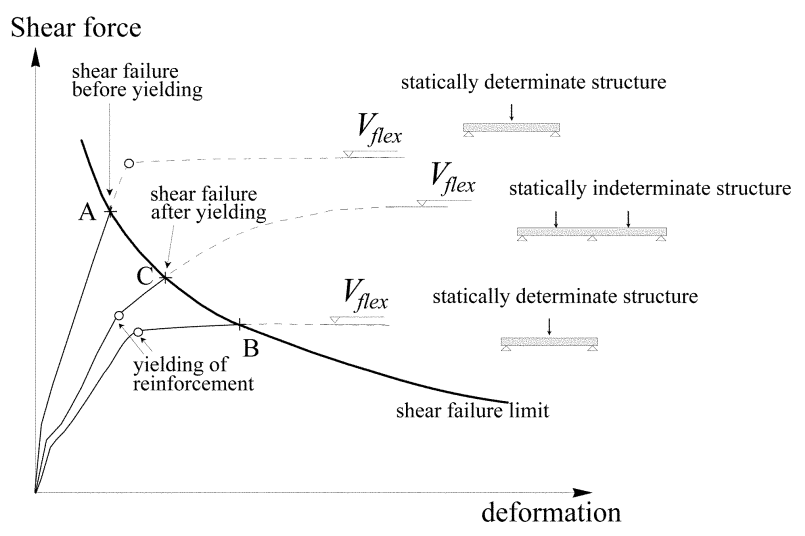

(b)

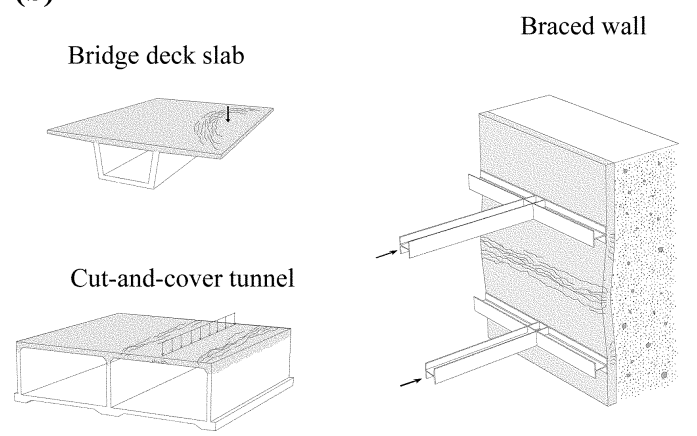

Fig. 2-Behavior of slabs without shear reinforcement: (a) shear failure before and after yielding of flexural reinforcement; and (b) examples of statically redundant structures without shear reinforcement.

ratio between the two applied loads was different for the 11 beams, which allowed varying the shear span of the specimens (this will be discussed in a following section). The ratio was kept approximately constant during each test. For some specimens in which two shear failures developed (Specimens SR6, SR7, and SR9), however, the ratio had to be modified between the first and second shear failures.

\section{Material properties}

Normal-strength concrete was used in all of the specimens. The compressive strength, modulus of elasticity, and tensile strength of concrete are detailed in Table 1, together with the age of each specimen at the time of testing. The properties of concrete were measured on $320 \mathrm{~mm}$ (12.6 in.) high concrete cylinders with a diameter equal to $160 \mathrm{~mm}$ (6.30 in.). The concrete compressive strength at the time of testing ranged from 42.4 to $52.8 \mathrm{MPa}$ (6150 to $7660 \mathrm{psi}$ ). The values of the modulus of elasticity, given in Table 1, correspond to the secant stiffness between compressive stresses 1 to $10 \mathrm{MPa}$ (145 to $1450 \mathrm{psi}$ ). The tensile strength was obtained from pure tension tests.

The composition of $1 \mathrm{~m}^{3}\left(1.308 \mathrm{yd}^{3}\right)$ of concrete was $929 \mathrm{~kg}$ $(2050 \mathrm{lb})$ of sand, $408 \mathrm{~kg}(900 \mathrm{lb})$ of gravel ranging from 4 to $8 \mathrm{~mm}$ ( 0.158 to $0.315 \mathrm{in}$.) in diameter, $521 \mathrm{~kg}(1150 \mathrm{lb})$ of gravel ranging from 8 to $16 \mathrm{~mm}$ (0.315 to $0.630 \mathrm{in}$.) in diameter, $440 \mathrm{~kg}(970 \mathrm{lb})$ of portland cement, and $190 \mathrm{~kg}$ $(418 \mathrm{lb})$ of water. The maximum size of the aggregate was $16 \mathrm{~mm}$ (0.63 in.). 

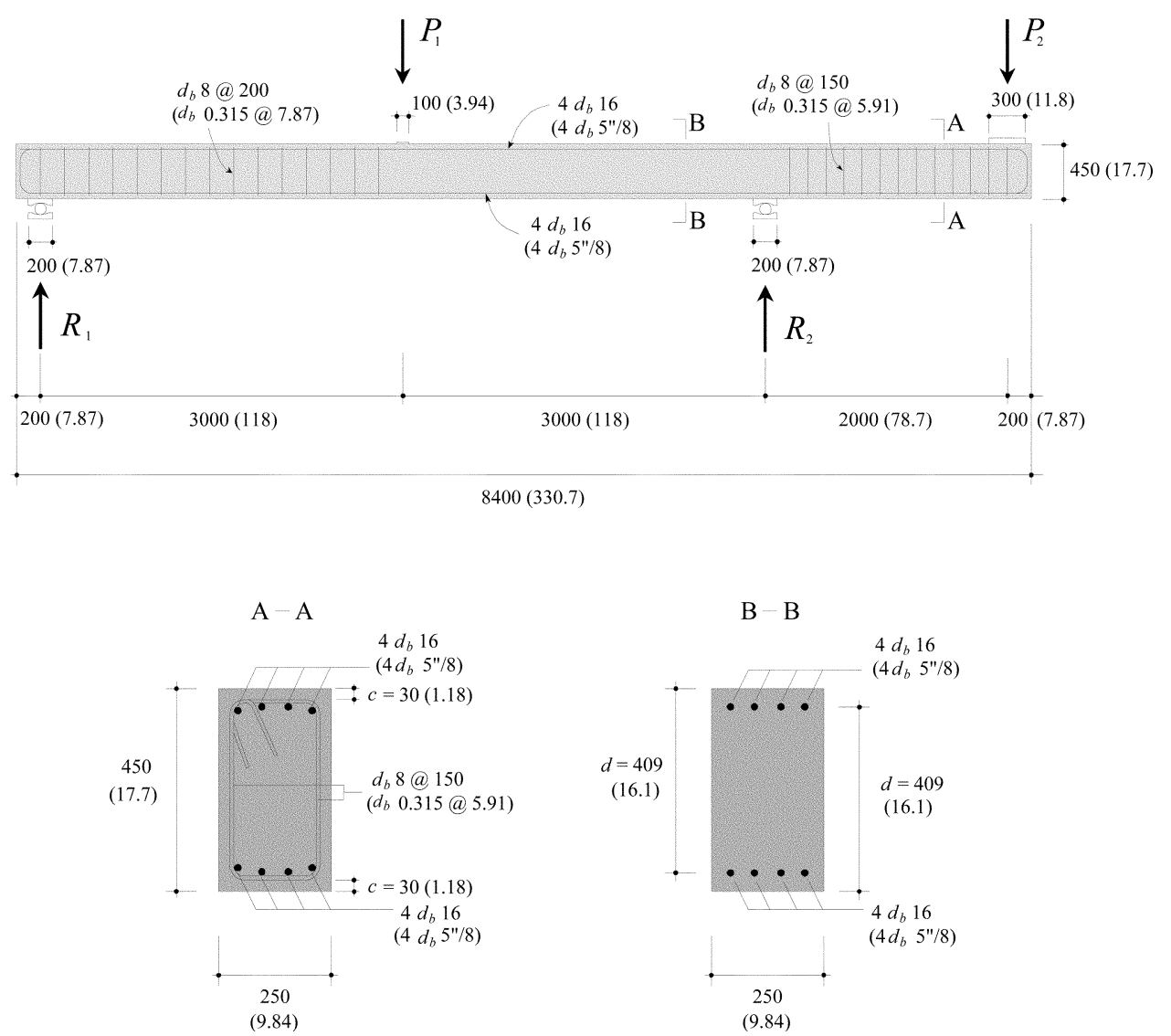

Fig. 3-Geometry and reinforcement. (Note: dimensions in mm [in.].)

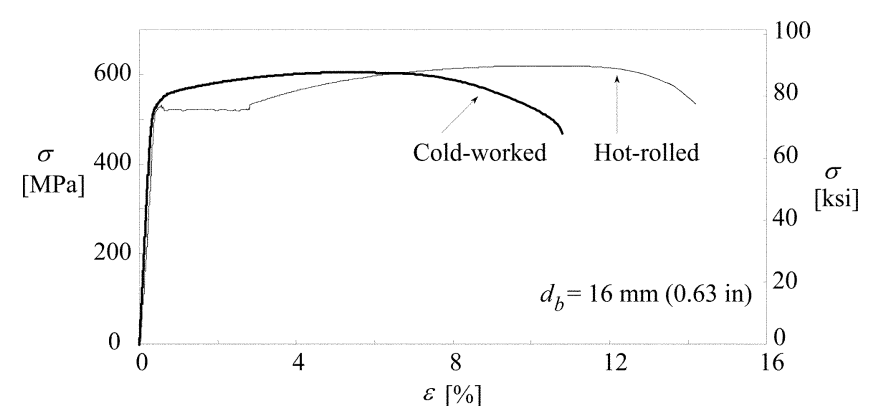

Fig. 4-Stress-strain diagrams of flexural reinforcement bars.

For Specimens SR2 to SR9, the flexural reinforcing steel was cold-worked, whereas for Specimens SR10 to SR12, the reinforcement was hot-rolled. The results of the tension tests with strains measured over a length of $150 \mathrm{~mm}$ (5.9 in.) are shown in Fig. 4 and Table 2. The loading speed before yielding for the tension tests was $10 \mathrm{MPa} / \mathrm{s}(1.45 \mathrm{ksi} / \mathrm{s})$ and the test was displacement-controlled thereafter.

\section{Measurements}

A view of the specimens and the test setup is shown in Fig. 5. Continuous measurements of the loads (applied by controlled displacements) were taken by integrated load cells at the hydraulic jacks. Additional measurements were taken by load cells placed below the bearings, allowing for redundancy in the force measurements.

The deflections of the specimens were measured using linearly variable displacement transducers (LVDTs) at the bottom surface. Five points were measured for each specimen
Table 1-Average values of concrete properties

\begin{tabular}{c|c|c|c|c}
\hline Specimen & $\begin{array}{c}\text { Age at } \\
\text { testing, days }\end{array}$ & $\begin{array}{c}f_{c}, \\
\mathrm{MPa}(\mathrm{psi})\end{array}$ & $\begin{array}{c}f_{c t}, \\
\mathrm{MPa}(\mathrm{psi})\end{array}$ & $\begin{array}{c}E_{c}, \\
\mathrm{MPa}(\mathrm{ksi})\end{array}$ \\
\hline SR2 & 37 & $43.1(6250)$ & $2.8(410)$ & $31,000(4490)$ \\
\hline SR3 & 79 & $50.6(7340)$ & $3.0(440)$ & $31,900(4630)$ \\
\hline SR4 & 102 & $47.5(6900)$ & $2.6(370)$ & $33,100(4790)$ \\
\hline SR5 & 107 & $47.6(6910)$ & $2.6(380)$ & $33,100(4800)$ \\
\hline SR6 & 288 & $52.7(7640)$ & $3.3(480)$ & $33,600(4880)$ \\
\hline SR7 & 291 & $49.1(7120)$ & $3.2(460)$ & $32,600(4730)$ \\
\hline SR8 & 299 & $49.2(7130)$ & $3.2(460)$ & $32,600(4730)$ \\
\hline SR9 & 311 & $52.8(7660)$ & $3.3(480)$ & $33,800(4900)$ \\
\hline SR10 & 95 & $42.4(6150)$ & $2.5(360)$ & $31,700(4590)$ \\
\hline SR11 & 106 & $42.9(6220)$ & $2.7(390)$ & $31,800(4620)$ \\
\hline SR12 & 121 & $43.5(6310)$ & $2.9(420)$ & $32,100(4650)$ \\
\hline
\end{tabular}

in the zone between supports and one at the tip of the cantilever (Fig. 6(a)).

The strains at the surface of the specimens were measured using omega-shaped extensometers with a measuring length of $100 \mathrm{~mm}$ (3.94 in.). The gauges were glued to the concrete surface near load $P_{1}$ and intermediate support $R_{2}$, at the level of the top and bottom flexural reinforcement along a length of $800 \mathrm{~mm}$ (31.5 in.) (Fig. 6(a)). Additionally, 331 displacement readings were taken at selected load stages between aluminum targets of a triangular mesh with a base measurement of $120 \mathrm{~mm}$ (4.72 in.). The mesh (Fig. 6(b)) covered the entire zone between applied load $P_{1}$ and intermediate support $R_{2}$. These displacements were measured using a portable LVDT device (digital strain gauge). Details of the various 


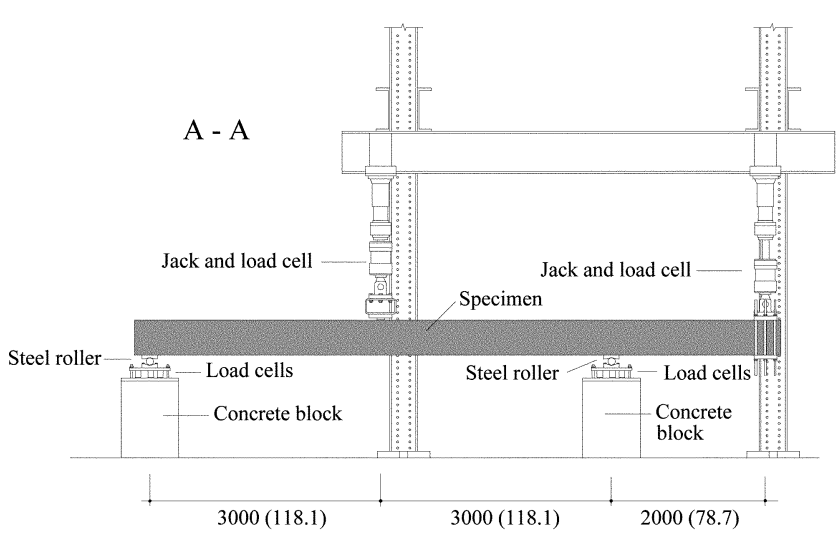

$3000(118.1)$

$3000(118.1)$

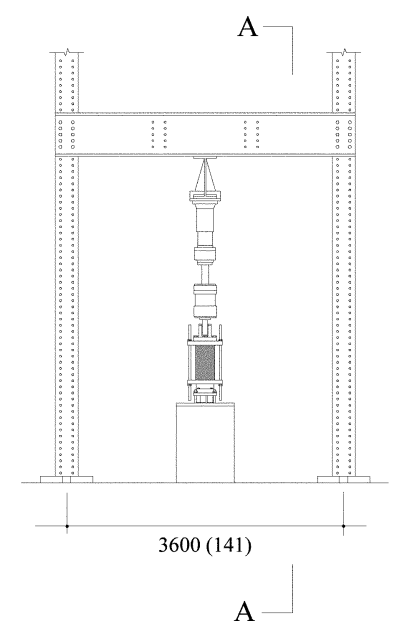

Fig. 5-Test setup. (Note: dimensions in mm [in.].)

Table 2-Average values of flexural reinforcement properties

\begin{tabular}{c|c|c}
\hline Test & Specimens SR2 to SR9 & Specimens SR10 to SR12 \\
\hline$d_{b}, \mathrm{~mm}(\mathrm{in})$. & $16(0.63)$ & $16(0.63)$ \\
\hline$f_{y}, \mathrm{MPa}(\mathrm{ksi})$ & $530(76.9)^{*}$ & $523(75.9)$ \\
\hline$f_{u}, \mathrm{MPa}(\mathrm{ksi})$ & $600(87.0)$ & $621(90.1)$ \\
\hline$\varepsilon_{u}, \%$ & 5.52 & 10.6 \\
\hline$f_{u} / f_{y}$ & 1.13 & 1.19 \\
\hline Type & Cold-worked & Hot-rolled \\
\hline
\end{tabular}

*Yield strength at $0.2 \%$ plastic strain.

measurements performed for the specimens can be found in References 10 and 11.

\section{Development of tests}

The load-midspan deflection curves for all of the specimens are shown in Fig. 7. Significant differences were observed on the failure mode of the various specimens depending on the applied loading ratio (shear span):

1. Specimens SR2 and SR11 failed in shear near the intermediate support (Fig. 8) before yielding of the flexural reinforcement and in an extremely brittle manner. A sudden propagation of a diagonal shear crack occurred for both specimens, followed by an almost total loss of load-carrying capacity. The measured crack openings of the shear crack at the last load step before failure were approximately $0.10 \mathrm{~mm}$ (0.004 in.) for Specimen SR2 and $0.20 \mathrm{~mm}(0.008 \mathrm{in}$.) for Specimen SR11.

2. Specimens SR6, SR7, and SR9 failed in shear with limited plastic strains in the flexural reinforcement. For the three specimens, an inclined shear crack first opened up to the compression zone. Contrary to Specimens SR2 and SR11, however, the development of this shear crack did not lead to the failure of the specimen. Thereafter, the crack progressed horizontally along the tensile flexural reinforcement. Simultaneously, the applied load $P_{1}$ dropped by approximately $20 \%$ for the three specimens. After this sudden drop, it was possible to reload Specimens SR6 and SR7 to an applied load $P_{1}$ of $27 \%$ and $13 \%$, respectively, larger than that at which the first inclined shear crack developed. At that moment, Specimens SR6 and SR7 failed in an extremely brittle manner by the development of a second shear crack (a)

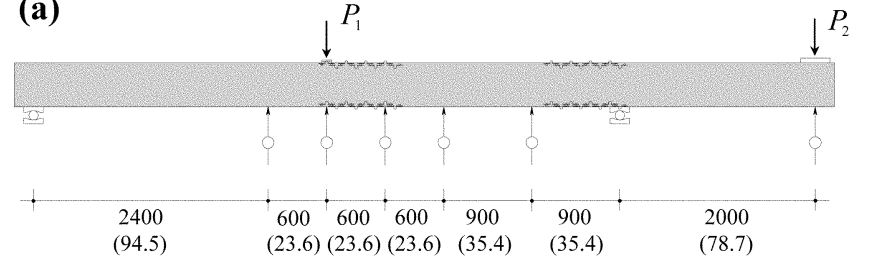

(b)

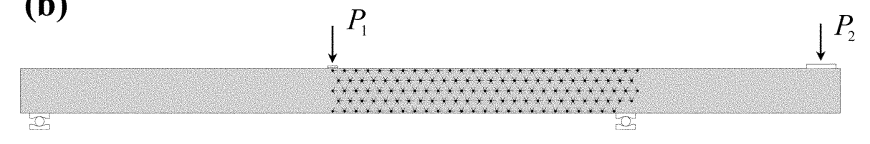

Fig. 6-Measurements: (a) Omega-shaped extensometers and LVDTs; and (b) strain gauge measurements. (Note: dimensions in $\mathrm{mm}$ [in.].)

(refer to Fig. 8 for first and second shear crack positions). For Specimen SR9, it was possible to reload $P_{1}$ to a load level equal to that at which the first inclined crack formed. At that stage, a second shear crack formed, and the load $P_{1}$ dropped $30 \%$. The test was then stopped because the maximal crack openings reached $60 \mathrm{~mm}$ (2.4 in.). It should be noted that, during reloading after the first failure, it was not always possible to keep the ratio between the applied loads $\left(P_{2} / P_{1}\right)$ equal to the one applied previously (refer to Fig. 7). This was not very significant for Specimens SR6 and SR9 (where failure developed at a similar ratio), but was notable for Specimen SR7 at failure (where the ratio increased from 0.11 to 0.51 at failure).

3. Specimens SR3, SR4, and SR8 also failed in shear but after extensive yielding of the flexural reinforcement in the zone below the applied load P1 (Fig. 8). Shear failures of these specimens were rather ductile, resulting from the propagation of well defined shear cracks (widths at midheight ranging from 1 to $3 \mathrm{~mm}$ [0.04 to $0.12 \mathrm{in}$.]) into the compression zone. The propagation of the inclined shear cracks led to a total loss of load-carrying capacity.

4. Specimens SR10 and SR12 (with hot-rolled reinforcement) developed considerable yielding of the flexural reinforcement in the zone below load $P_{1}$ (Fig. 8). For both specimens, a rather vertical shear crack developed in this region. At that stage, the applied load dropped 20\%. From then on, the deformation of the specimens increased under constant loads until the crack widths (at a level of tensile reinforcement) 

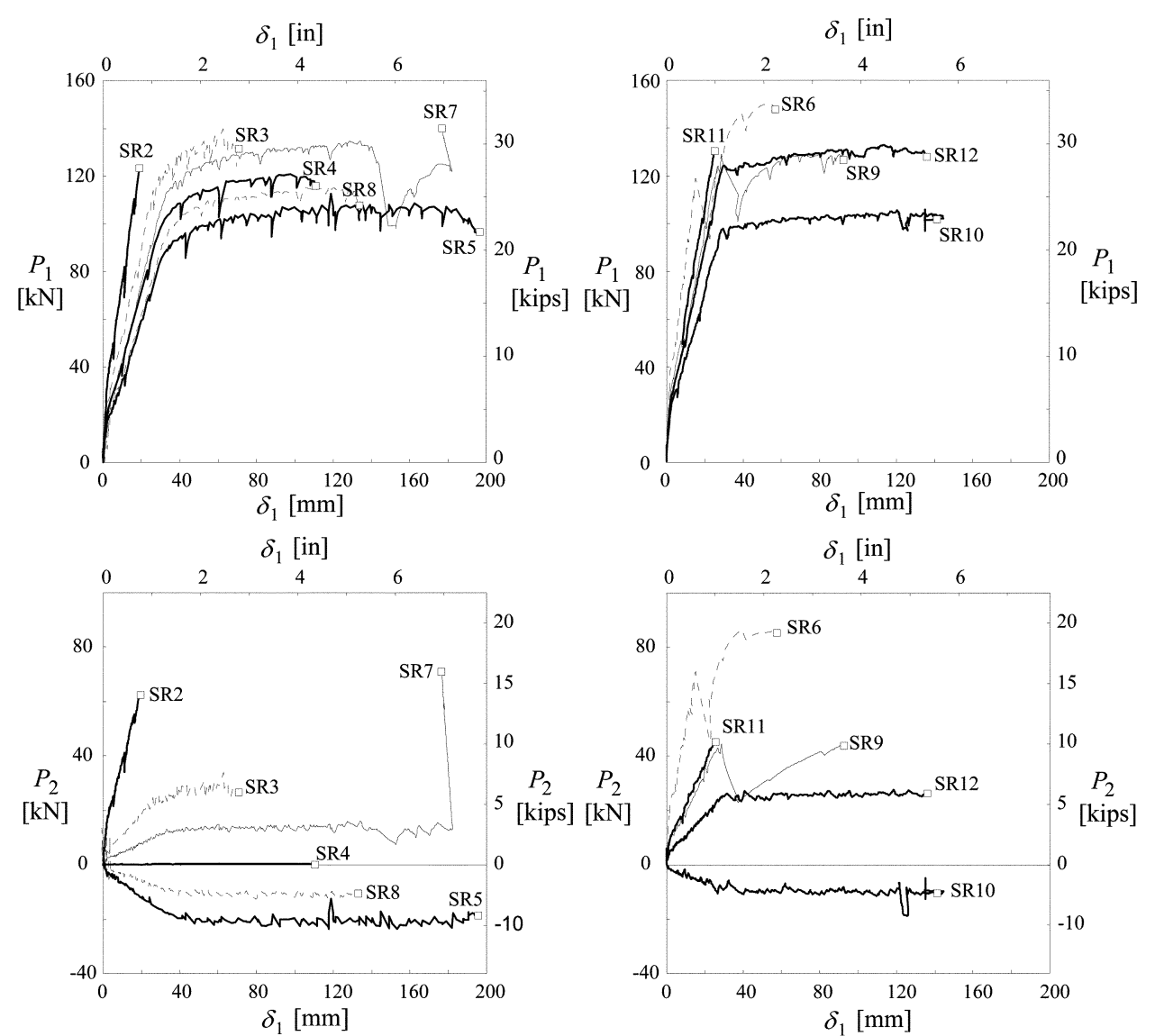

$\delta_{1}[\mathrm{in}]$

[kips]
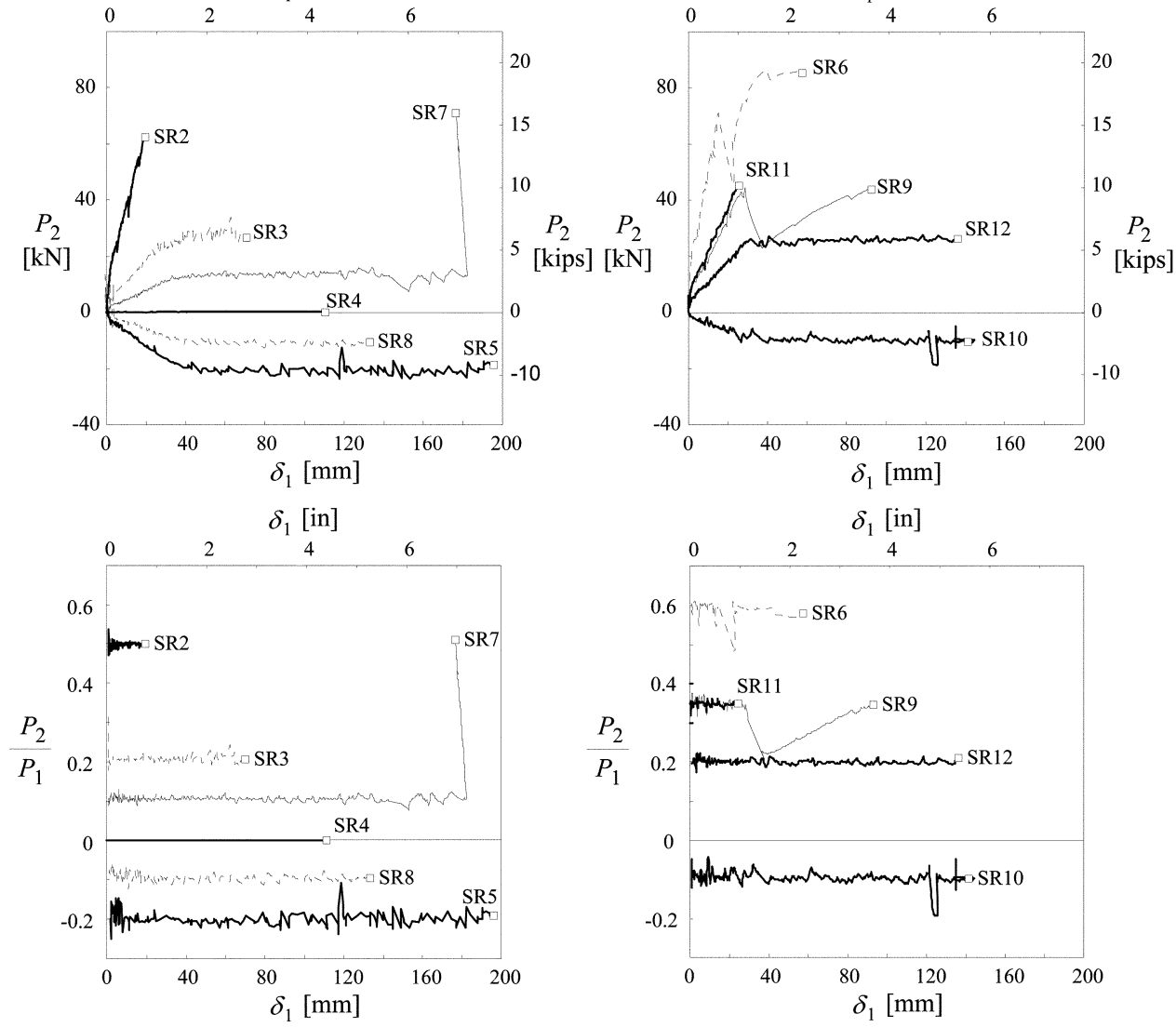

Fig. 7-Load-midspan deflection curves for all specimens and ratios $\mathrm{P}_{2} / \mathrm{P}_{1}$ during tests.

reached up to $30 \mathrm{~mm}$ (1.2 in.) and part of the concrete cover below the tensile reinforcement split. The tests were then stopped.

5. Specimen SR5 failed in bending with rupture of the flexural reinforcement in tension. The width of the flexural crack, measured at the last load step before failure, was $6 \mathrm{~mm}$ $(0.24 \mathrm{in}$.) at the level of flexural reinforcement.

A view of the specimens after testing, together with some details, are shown in Fig. 8. More information on the measurements can be found in References 10 and 11.

A summary of the main results is given in Table 3 . The shear force and bending moment at failure, including selfweight ( $V_{R}$ and $M_{R}$, respectively), are given at a cross section placed at $d / 2$ away from the axis of the applied load $P_{1}$ or of the intermediate support $R_{2}$, depending on the position of the failure zone. The rotations at failure $\left(\psi_{R}\right.$, comprising both elastic and plastic rotations) are estimated by integrating the continuous measurements of the strains in the top and bottom fibers, as indicated in Fig. 9. The length of the beam where the rotation is calculated (equal to $1.96 \mathrm{~d}$, refer to Fig. 9) corresponds approximately for all specimens to the distance between the applied load and the flexural crack from which the critical shear crack (shear crack leading to failure) developed (Fig. 8). A comparison of the rotations calculated using this criterion and those obtained from the deflections of the beam shows good agreement. ${ }^{11}$ It should be noted that both the rotation at failure and the shear span (a) depend on the position of the failure zone. For Specimens SR3 to SR6, SR8 to SR10, and SR12, they are obtained according to Fig. 9(a), whereas Fig. 9(b) applies to Specimens SR2, SR7, and SR11.

\section{Kinematics of critical shear crack}

Taking advantage of the measurements performed on the triangular mesh (Fig. 6(b)), the normal $(\Delta u)$ and tangential 


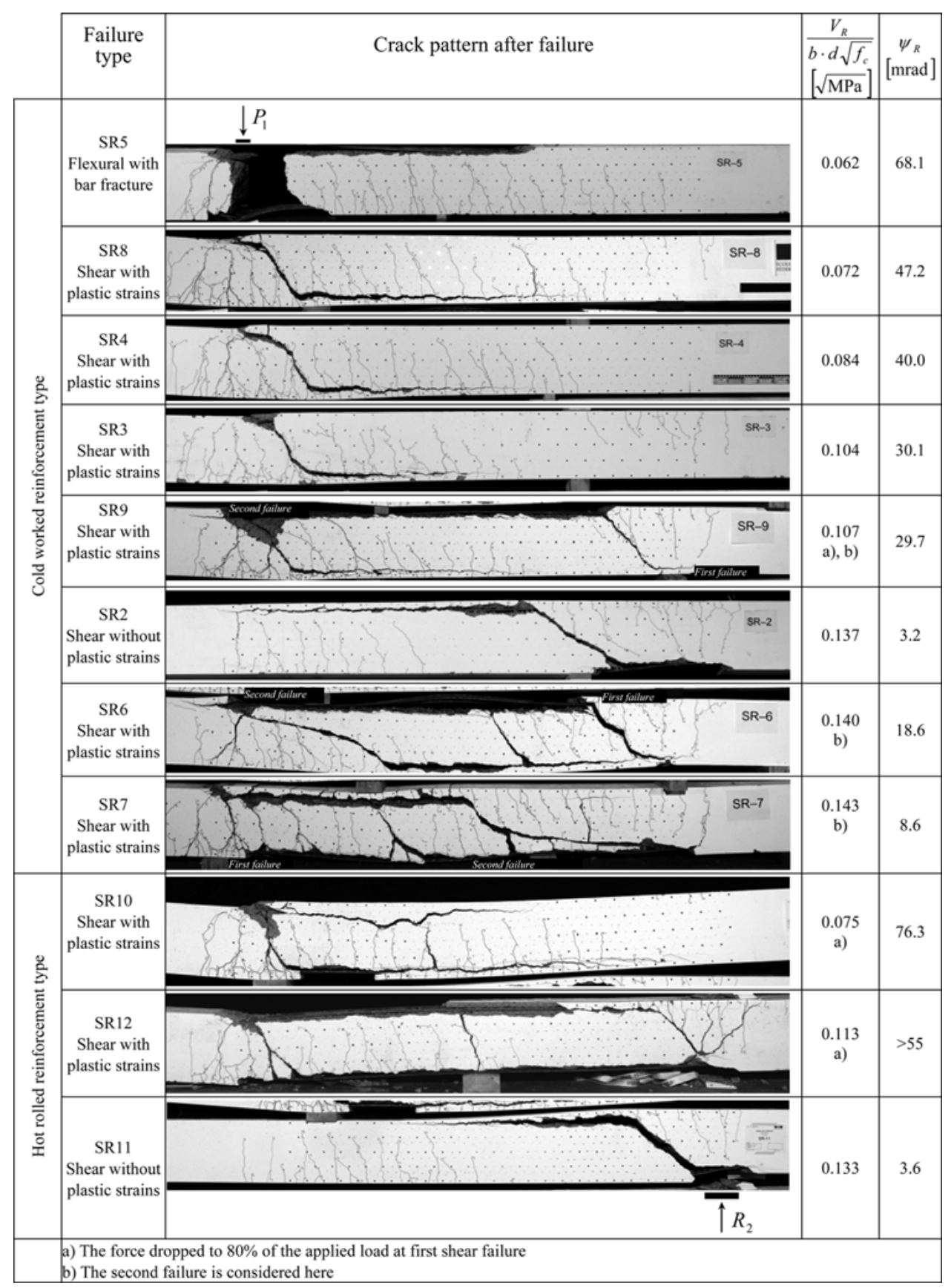

Fig. 8-Failure type and crack pattern for all slab strips (ordered by increasing shear strengths for each reinforcement type). (Note: $1 \mathrm{MPa}=145 \mathrm{psi}$.)

$(\Delta v)$ relative displacements between the lips of the critical crack can be calculated. ${ }^{10,11}$ For instance, Fig. 10 plots the results for Specimen SR4. The trend in the relative displacements suggests that the center of the rotation of the crack is located near the tip of the crack, moving toward the load introduction plate as the crack develops. This result is consistent with the measurements detailed in Reference 12.

It can be seen in Fig. 10 that although only normal relative displacements initially develop along the critical shear crack, tangential displacements also develop thereafter. A noticeable increase both in the normal and tangential displacements occurs after yielding (Fig. 10(b)). This result is consistent for the other specimens failing after yielding of the flexural reinforcement. ${ }^{11}$
ROTATION CAPACITY AND SHEAR STRENGTH OF PLASTIC HINGES BASED ON CSCT

The normalized shear stress is plotted versus the rotation in the failure region for all of the specimens in Fig. 11. It can be noted that the rotation at failure $\psi_{R}$ is larger for specimens with hot-rolled reinforcement than those with cold-worked reinforcement for the same level of shear stress. Also, it can be noted in Fig. 11 that the rotation at failure decreases with increasing shear forces. This result is consistent for the two types of reinforcing steel and all failure modes.

Such behavior can be explained with the help of the CSCT (interpretations based on a mechanical approach can also be found in Vaz Rodrigues ${ }^{10}$ ). The CSCT can be applied to both one- and two-way slabs $8,9,13$ and proposes that the shear strength, traditionally correlated to the square root of the 
Table 3-Tested slab strips: main results at failure and calculated values

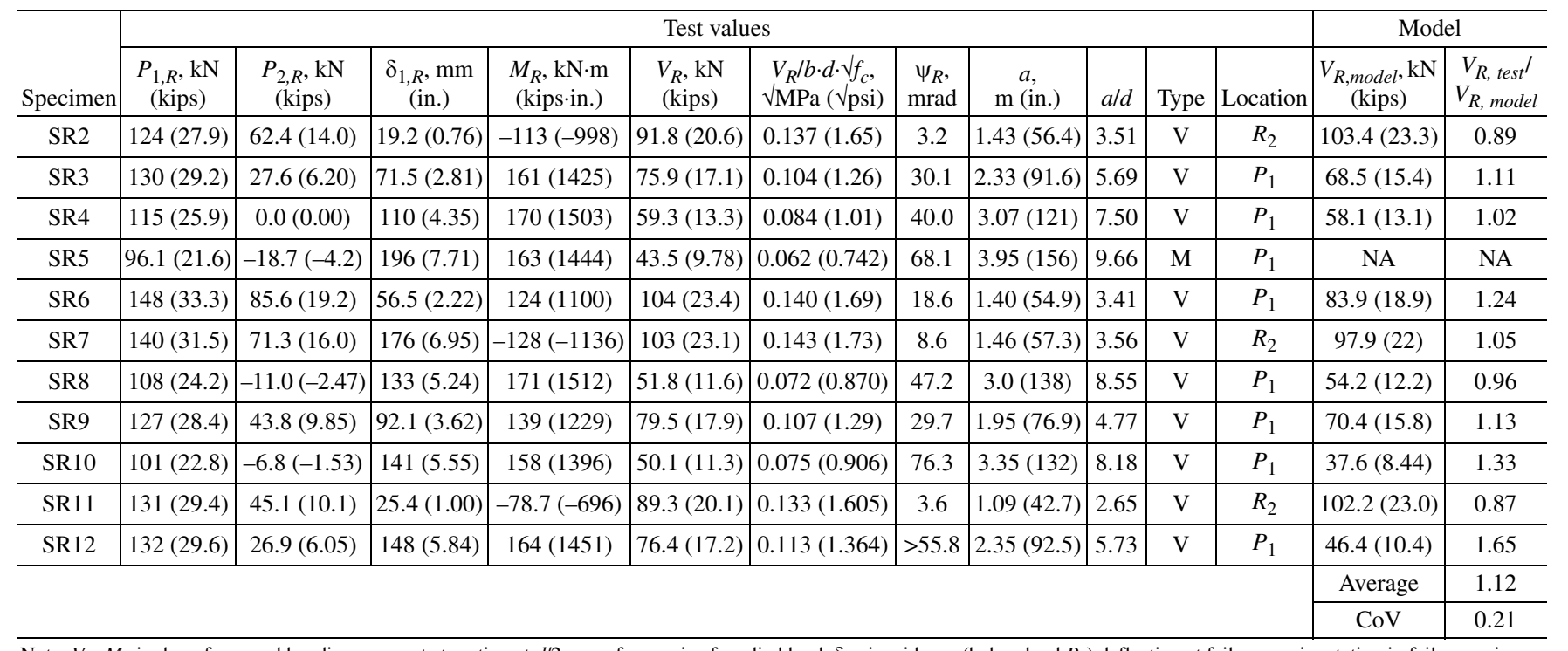

Note: $V_{R}, M_{R}$ is shear force and bending moment at section at $d / 2$ away from axis of applied load; $\delta_{1 R}$ is midspan (below load $P_{1}$ ) deflection at failure; $\psi_{R}$ is rotation in failure region, integrated along length of $1.96 \cdot d ; a$ is equivalent shear span $\left(=M_{R} / V_{R}+d / 2\right)$; Location is failure location $\left(R_{2}\right.$ is near intermediate support, $P_{1}$ is near applied load at midspan); and NA is not available.

(a)

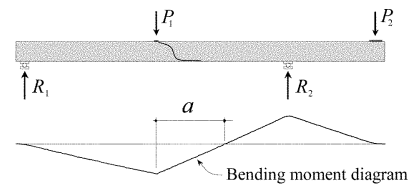

(b)

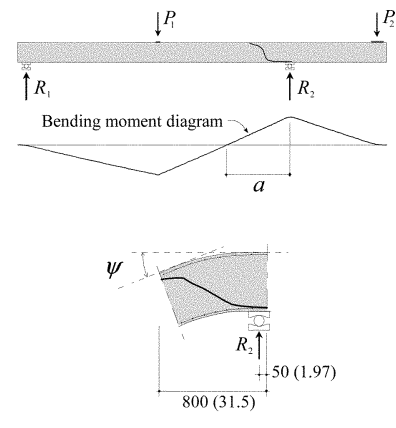

Fig. 9-Definition of shear span a and measured rotation $\psi$ according to location of shear failure: (a) critical shear crack at midspan; and (b) critical shear crack at intermediate support.

compressive strength of concrete, ${ }^{4,14}$ depends on the roughness and on the width of a critical shear crack (shear crack leading to failure). According to the CSCT, the critical shear crack develops partly along the inclined theoretical compression strut carrying shear (refer to Fig. 12) and limits the strength of the member with respect to the flexural capacity (as the strength of the inclined compression strut is reduced due to the presence of the crack).

The hypothesis of the dependence of the shear strength on the width $(w)$ and roughness (characterized by the maximum aggregate size, $d_{g}$ ) of the critical shear crack can be written as 9

$$
\frac{V_{R}}{b \cdot d \cdot \sqrt{f_{c}}}=f\left(w, d_{g}\right)
$$

where $b$ is the width of a slab strip, $d$ is the effective depth, and $f_{c}$ is the compressive strength of concrete measured in a cylinder. For beams failing in shear without development of plastic strains in the flexural reinforcement, the crack width (w) can be estimated as 9

$$
w \propto \varepsilon \cdot d
$$

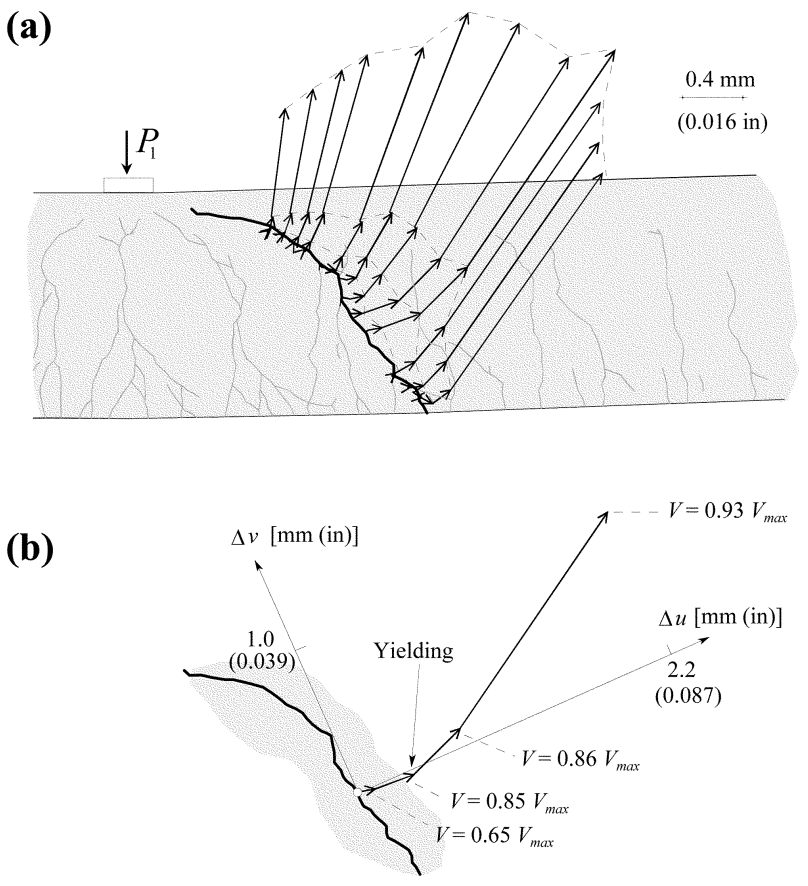

Fig. 10-Measurements of relative displacement between lips of critical shear crack for Specimen SR4: (a) evolution along critical shear crack; and (b) normal ( $\Delta \mathrm{u})$ and tangential $(\Delta \mathrm{v})$ relative displacements.

where $\varepsilon$ is a reference strain in the beam (a longitudinal strain calculated at a control section ${ }^{8}$ [refer to Fig. 12]). A formulation of the failure criterion (Eq. (1)) accounting for this hypothesis (Eq. (2)) can be found in ${ }^{9}$

$$
\begin{gathered}
\frac{V_{R}}{b \cdot d \sqrt{f_{c}}}=\frac{1}{6} \cdot \frac{2}{1+120 \frac{\varepsilon \cdot d}{16+d_{g}}} \text { SI units (MPa, mm) or } \\
\frac{V_{R}}{b \cdot d \sqrt{f_{c}}}=2 \cdot \frac{2}{1+120 \frac{\varepsilon \cdot d}{\frac{5^{\prime \prime}}{8}+d_{g}}} \text { U.S. customary units (psi, in.) }
\end{gathered}
$$




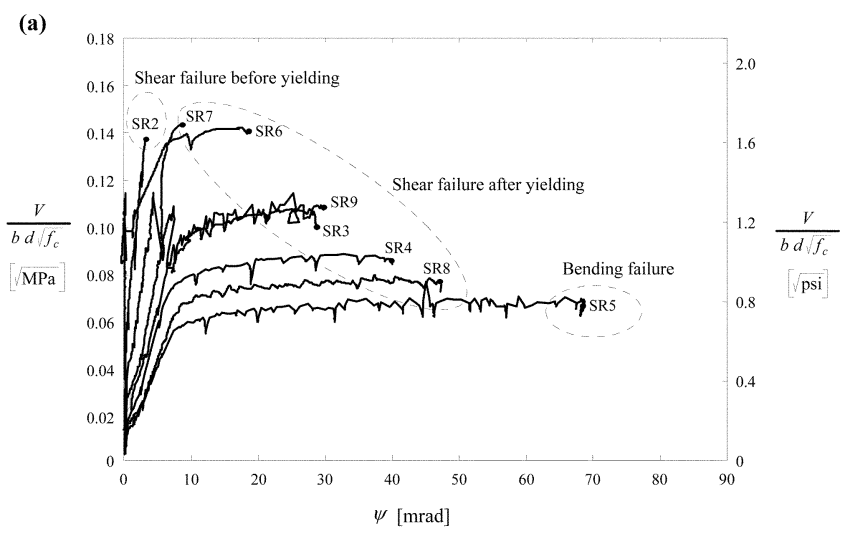

(b)

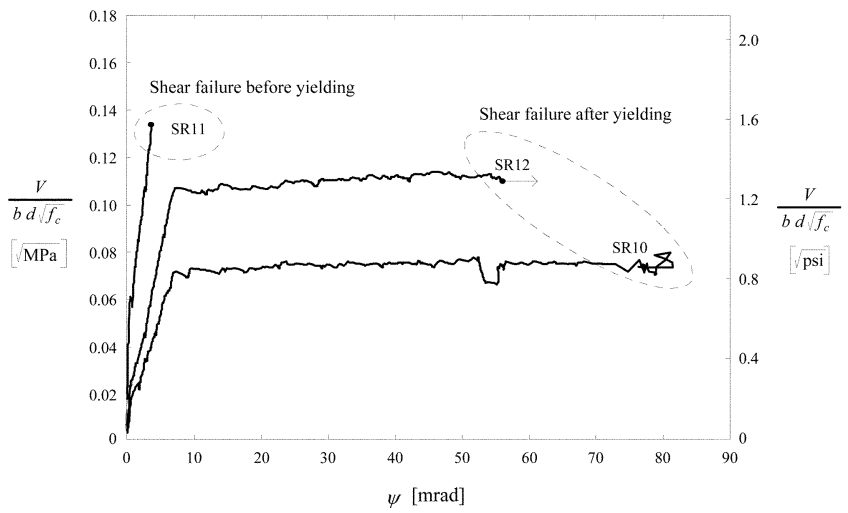

Fig. 11-Normalized shear stress versus rotation for all slab strips: (a) cold-worked reinforcement; and (b) hot-rolled reinforcement.

(a) Critical shear crack

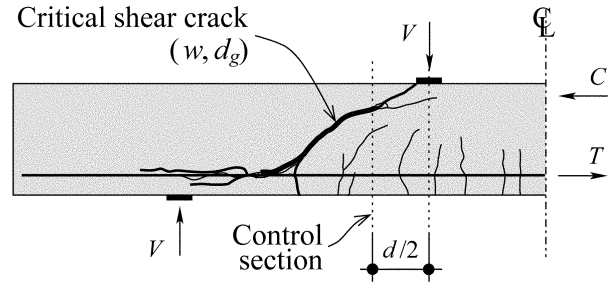

(b) Theoretical

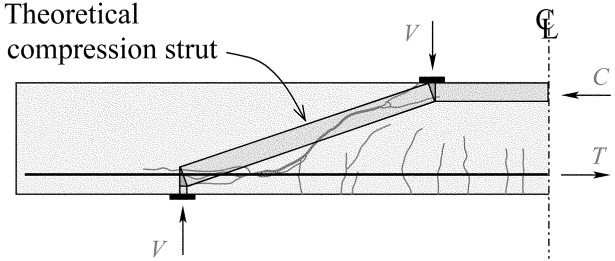

Fig. 12-Critical shear crack developing in one-way slab subjected to point loading: (a) position of critical shear crack and of control section; and (b) development of critical shear crack along theoretical compression strut.

Figure 13(b) compares, with good agreement, the results obtained using Eq. (3) to the test results detailed in this paper as a function of the shear span to effective depth ratio.

With respect to members developing plastic strains in the flexural reinforcement, and according to the CSCT, a shear failure may also develop after yielding of the flexural reinforcement. This is justified by the fact that the increase in the opening of the cracks (as rotations increase during the plastic
- Cold-worked reinforcement (shear failure)

$\square$ Hot-rolled reinforcement (shear failure)

○ SR5 (flexural failure)
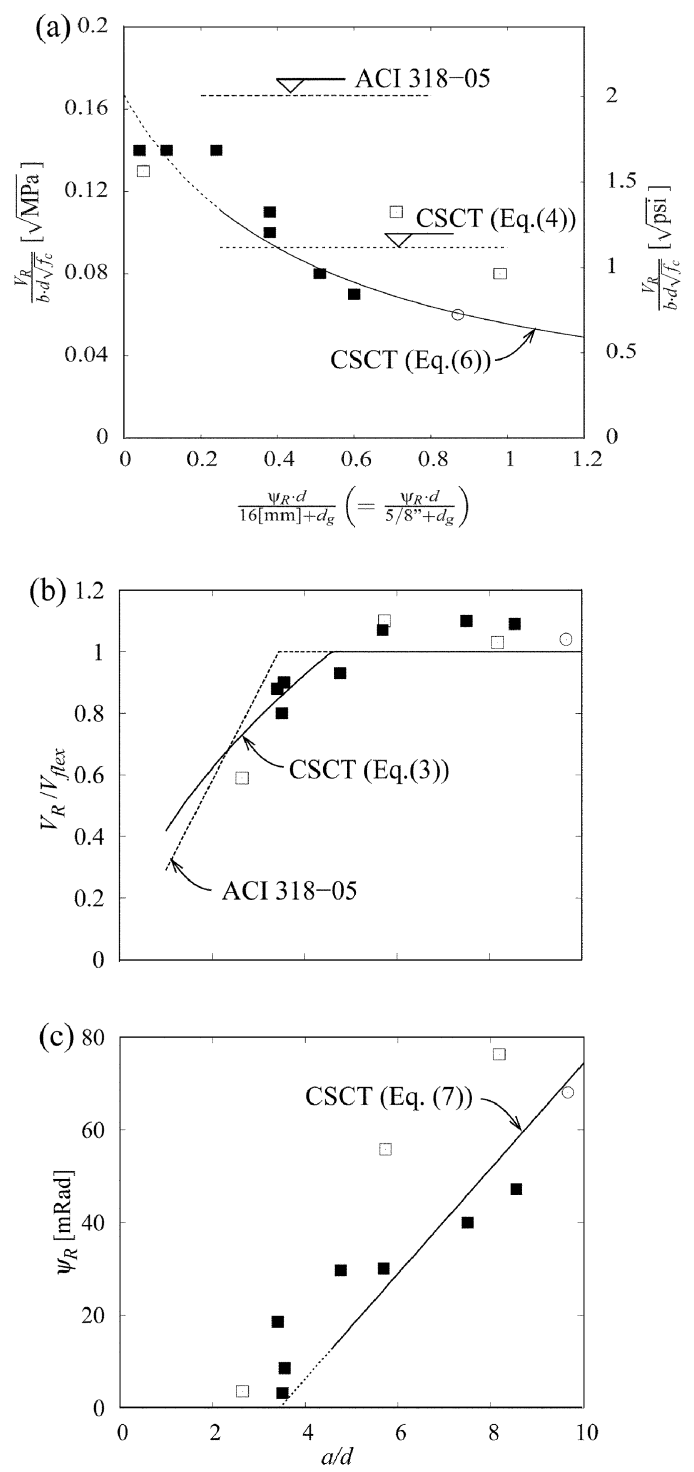

Fig. 13-Comparison of test results with ACI 318-05' and $C S C T^{8,9}$ : (a) shear strength as function of rotation capacity; (b) shear strength as function of shear span to effective depth ratio; and (c) rotation capacity as function of shear span to effective depth ratio.

plateau) limits the amount of shear that can be transferred by the various shear-carrying mechanisms in the member. ${ }^{9}$ Thus, for low levels of shear force acting in a plastic hinge, larger rotations (leading to larger crack widths) can be developed. A similar conclusion has been observed by Guandalini et al. ${ }^{15}$ for punching shear based on the results of an experimental program on two-way slabs without transverse reinforcement (where the measured rotations of the members at failure increased for lower levels of the applied shear force).

For beams developing plastic rotations, a simplified approach was proposed for design purposes based on the CSCT, ${ }^{9}$ reducing the shear strength with respect to Eq. (3) to account for the fact that yielding of the longitudinal reinforcement produces a notable increase in the width of the critical shear crack. This formula ${ }^{9}$ (setting partial safety factors or strength reduction factors to 1.0 ) results 


$$
\begin{gathered}
\frac{V_{R}}{b \cdot d \sqrt{f_{c}}}=\frac{0.3}{1+68 \cdot \frac{d}{16+d_{g}} \cdot \frac{f_{y}}{E_{s}}} \text { SI units (MPa, mm) or } \\
\frac{V_{R}}{b \cdot d \sqrt{f_{c}}}=\frac{3.6}{1+68 \cdot \frac{d}{\frac{5^{\prime \prime}}{8}+d_{g}} \cdot \frac{f_{y}}{E_{s}}} \text { U.S. customary units (psi, in.) }
\end{gathered}
$$

Equation (4) is currently considered in the Swiss Code for Structural Concrete, SIA 262 (2003), ${ }^{16}$ and is particularly suitable for preliminary design purposes in which the rotation $\psi_{R}$ is usually unknown. Figure 13(a) compares the results of the current test program to Eq. (4), where it can be noted that a reasonable estimate of the maximum shear that can be transmitted by a plastic hinge is obtained.

Based on the experimental results of this paper, however, a more suitable relationship than Eq. (4) can be proposed for beams developing plastic strains accounting for the rotation capacity at failure. This expression is based on the CSCT hypothesis (Eq. (1)), where the width of the critical shear crack is estimated as

$$
w \propto \psi \cdot d
$$

where $\psi$ is the rotation of the plastic hinge, as defined in Fig. 9. The proposed failure criterion based on Eq. (5) is

$$
\begin{gathered}
\frac{V_{R}}{b \cdot d \sqrt{f_{c}}}=\frac{1}{6} \cdot \frac{1}{1+2 \cdot \frac{\psi \cdot d}{16+d_{g}}} \text { SI units }(\mathrm{MPa}, \mathrm{mm}) \text { or } \\
\frac{V_{R}}{b \cdot d \sqrt{f_{c}}}=2 \cdot \frac{1}{1+2 \cdot \frac{\psi \cdot d}{\frac{5^{\prime \prime}}{8}+d_{g}}} \text { U.S. customary units (psi, in.) }
\end{gathered}
$$

For $\psi=0$, Eq. (6) predicts the same shear strength as ACI $318-05,{ }^{4}$ decreasing this strength as $\psi$ increases. This equation is thus in agreement to other works, ${ }^{9,17}$ showing that for large values of the product $\psi \cdot d$ (for instance, for slab strips with low flexural reinforcement ratios or for thick members), the strength predicted by ACI $318-05^{4}$ might be overestimated and unsafe. According to Eq. (6), the product $\psi \cdot d$ accounts for the width of the critical shear crack and thus reduces the shear strength for increasing openings of the critical shear crack. This consideration introduces a size effect on the rotation capacity of plastic hinges, which is consistent with the observations made by other researchers. ${ }^{3}$ A comparison of Eq. (6) to the test results presented in this paper is shown in Fig. 13(a) and Table 3. A good fitting is obtained for the various failure modes and reinforcement types (being more conservative for members with hot-rolled reinforcement).

Another interesting result of Eq. (6) can be obtained for members failing once the plastic plateau is reached by replacing the value of the shear strength $\left(V_{R}\right)$ as a function of the flexural strength and shear span: $V_{\text {flex }}=M_{\text {flex }} / a$. The value of $M_{\text {flex }}$ can be estimated according to the theory of plasticity, as $M_{f l e x}=\rho b d_{2} f_{y}\left(1-\rho f_{y} /\left(2 f_{c}\right)\right)$, which can be approximated for usual cases as $M_{\text {flex }}=\rho b d^{2} f_{y} \cdot 0.9$. In so doing, the rotation capacity $\left(\psi_{R}\right)$ results

$$
\begin{gathered}
\psi_{R}=\frac{16+d_{g}}{2 \cdot d} \cdot\left(\frac{a}{d} \cdot \frac{\sqrt{f_{c}}}{6 \cdot\left(\rho \cdot f_{y} \cdot 0.9\right)}-1\right) \text { SI units (MPa, mm) or } \\
\psi_{R}=\frac{\frac{5^{\prime \prime}}{8}+d_{g}}{2 \cdot d} \cdot\left(\frac{a}{d} \cdot \frac{2 \cdot \sqrt{f_{c}}}{\left(\rho \cdot f_{y} \cdot 0.9\right)}-1\right) \quad \text { U.S. customary units (psi, in.) }
\end{gathered}
$$

where the rotation capacity is shown to depend on the effective depth (size effect), slenderness of the beam ( $a / d$ ratio, refer to Fig. 1), reinforcement ratio, yield strength of flexural reinforcement, aggregate size, and concrete strength in compression. Equation (7) is compared in Fig. 13(c) to the tests detailed in this paper. The analytical and experimental results show the major influence on the rotation capacity of the slenderness of the members, which thus proves to depend on the opening of the shear critical crack and not only on the gradient of curvatures in the shear critical region.

\section{CONCLUSIONS}

The shear strength and the rotation capacity of members subjected to one-way shear without transverse reinforcement are investigated in this paper. The results of a test series of 11 slab strips are presented and analyzed. On that basis, the following conclusions are found:

1. Failure after yielding of the flexural reinforcement may be governed by flexure (rupture of the tensile reinforcement or crushing of the compression zone) or by shear.

2. Shear failures limit the rotation capacity of plastic hinges in one-way members. This is significant for statically redundant structures where a certain level of ductility is required to develop the full strength of the system.

3. Failures in shear after yielding of the flexural reinforcement develop due to the fact that the width of the cracks increase for increasing rotations and, thus, the strength of the various shear-carrying mechanisms of the member is reduced. Consequently, the rotation capacity of plastic hinges increases for decreasing values of the shear force.

4. Slab strips with hot-rolled (high-ductility) reinforcement exhibit a larger rotation capacity after yielding than slab strips with cold-worked reinforcement; however, this increase in the ductility can be neglected for practical purposes.

5. A consistent approach based on the CSCT is presented to estimate the rotation capacity of plastic hinges in one-way members accounting for shear and leading to a design equation.

6 . The proposed design equation accounts for the influence on the rotation capacity of plastic hinges in one-way members of the effective depth, shear span, flexural reinforcement ratio, yield strength of flexural steel, concrete strength in compression, and aggregate size.

\section{ACKNOWLEDGMENTS}

The authors would like to gratefully acknowledge the support and funding of the Swiss Federal Road Authority and the Fundação para a Ciência e a Tecnologia (Portugal), Grant FCT/BD/13259/2003, which made the experimental and theoretical studies possible.

modulus of elasticity of reinforcemen

$f_{c}=$ compressive strength of concrete measured in cylinder

$f_{c t}=$ tensile strength of concrete

$f_{u}=$ tensile strength of reinforcement 


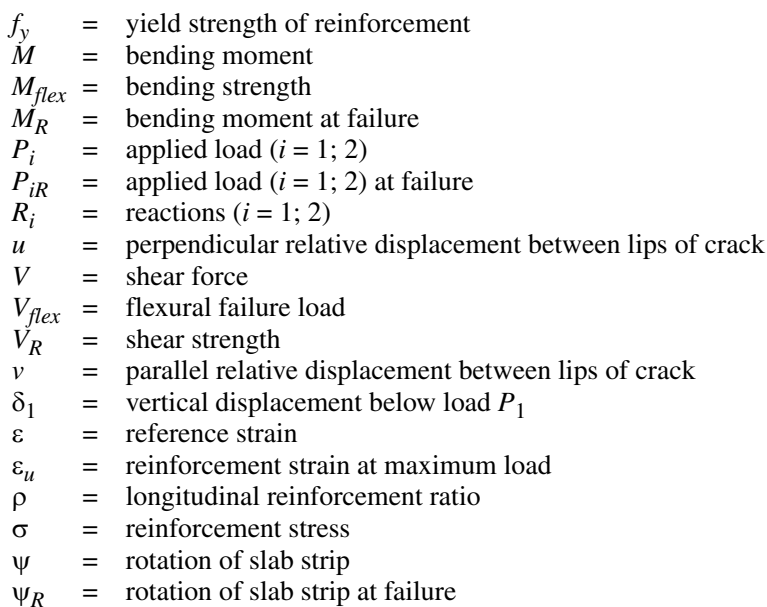

\section{REFERENCES}

1. Alvarez, M.; Köppel, S.; and Marti, P., "Rotation Capacity of Reinforced Concrete Slabs," ACI Structural Journal, V. 97, No. 2, Mar.Apr. 2000, pp. 235-242.

2. Bigaj, A. J., "Structural Dependence of Rotation Capacity of Plastic Hinges in RC Beams and Slabs," thesis, Delft University of Technology, the Netherlands, 1999, $229 \mathrm{pp}$.

3. CEB, "Ductility of Reinforced Concrete Structures-Synthesis Report and Individual Contributions," Bulletin 242, Comité Euro-international du Béton, Lausanne, Switzerland, 1998, 332 pp.

4. ACI Committee 318, "Building Code Requirements for Structural Concrete (ACI 318-05) and Commentary (318R-05)," American Concrete Institute, Farmington Hills, MI, 2005, 430 pp.

5. Eurocode 2, "Design of Concrete Structures," Part 1-1, General Rules and Rules for Buildings, prEN 1992-1-1, 2004, 222 pp.

6. Lee, J.-Y., and Kim, U.-Y., "Effect of Longitudinal Tensile Reinforcement Ratio and Shear Span-Depth Ratio on Minimum Shear Reinforcement in Beams," ACI Structural Journal, V. 105, No. 2, Mar.-Apr. 2008, pp. 134-144.
7. Kani, M. W.; Huggins, M. W.; and Wittkopp, R. R., "Kani on Shear in Reinforced Concrete," Department of Civil Engineering, University of Toronto, Toronto, ON, Canada, 1979, $97 \mathrm{pp}$.

8. Muttoni, A., "Shear and Punching Strength of Slabs without Shear Reinforcement," ("Schubfestigkeit und Durchstanzen von Platten ohne Querkarftbewehrung"), Beton-und Stahlbetonbau, V. 98, No. 2, 2003 , pp. 74-84. (in German)

9. Muttoni, A., and Fernández Ruiz, M., "Shear Strength of Members without Transverse Reinforcement as a Function of the Critical Shear Crack Width," ACI Structural Journal, V. 105, No. 2, Mar.-Apr. 2008 , pp. $163-172$.

10. Vaz Rodrigues, R., "Shear Strength of Reinforced Concrete Bridge Deck Slabs," PhD thesis, Nr. 3739, École Polytechnique Fédérale de Lausanne, Lausanne, Switzerland, 2007, 289 pp.

11. Vaz Rodrigues, R., and Muttoni, A., "Shear Strength without Stirrups after Yielding of RC Slab Strips-Test Report," (Influence des déformations plastiques de l'armature de flexion sur la résistance à l'effort tranchant des poutres sans étriers. Rapport d'essai), École Polytechnique Fédérale de Lausanne, Lausanne, Switzerland, 2007, 77 pp. (in French)

12. Muttoni, A., and Thürlimann, B., "Shear Tests on Beams and Slabs without Shear Reinforcement" ("Schubversuche an Balken und Flachdecken ohne Schubbewerung"), Institut für Baustatik und Konstruktion, ETH Zürich, 1986, 12 pp. http://is-beton.epfl.ch/Publications/198x/Muttoni86.pdf

13. Muttoni, A., "Punching Shear Strength of Reinforced Concrete Slabs without Transverse Reinforcement," ACI Structural Journal, V. 105, No. 4 July-Aug. 2008, pp. 440-450.

14. Moody, K. G.; Viest, M.; Elstner, R. C.; and Hognestad, E., "Shear Strength of Reinforced Concrete Beams-Part 1: Tests of Simple Beams," ACI Journal, Proceedings V. 51, No. 4, Apr. 1954, pp. 317-332.

15. Guandalini, S.; Burdet, O. L.; Muttoni, A., "Punching Tests of Slabs with Low Reinforcement Ratios," ACI Structural Journal, V. 106, No. 1, Jan.-Feb. 2009, pp. 87-95.

16. SIA, Code 262 for Concrete Structures, Swiss Society of Engineers and Architects, Zürich, Switzerland, 2003, 94 pp.

17. Collins, M. P., and Kuchma, D., "How Safe Are Our Large, Lightly Reinforced Concrete Beams, Slabs, and Footings?" ACI Structural Journal, V. 96, No. 4, July-Aug. 1999, pp. 482-490. 